\title{
Load Dependence of Proximal Tubular Bicarbonate Reabsorption in Chronic Metabolic Alkalosis in the Rat
}

\author{
David A. Maddox and F. John Gennari \\ Department of Medicine, University of Vermont College of Medicine, Burlington, Vermont 05405
}

\begin{abstract}
Studies were undertaken in Munich-Wistar rats to determine whether maintenance of chronic metabolic alkalosis (CMA) is associated with an increase in proximal $\mathrm{HCO}_{3}^{-}$reabsorption, or whether a reduction in glomerular filtration rate (GFR) is required to sustain the elevated plasma $\mathrm{HCO}_{3}^{-}$concentration. Superficial single nephron glomerular filtration rate (SNGFR), and absolute proximal $\mathrm{HCO}_{3}^{-}\left(\mathrm{APR}_{\mathrm{HCO}_{3}}\right)$ and water $\left(\mathrm{APR}_{\mathrm{H}_{2} \mathrm{O}}\right)$ reabsorption were measured $20 \pm 3 \mathrm{~d}$ after the induction of $\mathrm{CMA}$ in eight rats and the results compared with seven age-matched control animals. Plasma $\left[\mathrm{HCO}_{3}^{-}\right]$was $39.1 \pm 1.8 \mathrm{mM}$ in CMA rats compared with $26.0 \pm 0.4 \mathrm{mM}$ in controls $(P<0.001)$. In the CMA rats, SNGFR was $44.8 \pm 1.1 \mathrm{vs.} 38.2 \pm 2.1 \mathrm{nl} / \mathrm{min}$ in controls $(P<0.025)$. As a result, the single nephron filtered load of $\mathrm{HCO}_{3}^{-}\left(\mathrm{FL}_{\mathrm{HCO}_{3}}\right)$ increased from $1,147 \pm 61 \mathrm{pmol} / \mathrm{min}$ in control to $2,040 \pm 108 \mathrm{pmol} / \mathrm{min}$ in CMA $(P<0.001) . A P_{\mathrm{HCO}_{3}}$ increased by $>65 \%$, from $970 \pm 65 \mathrm{pmol} / \mathrm{min}$ in control to $1,624 \pm 86$ $\mathrm{pmol} / \mathrm{min}$ in CMA $(P<0.001)$. APR $_{\mathrm{H}_{2} \mathrm{O}}$ increased from 18.4 \pm 1.6 $\mathrm{nl} / \mathrm{min}$ in control to $24.0 \pm 0.8 \mathrm{nl} / \mathrm{min}$ in CMA $(P<0.005)$. Tubular hypertrophy resulted in an increase in the length of the proximal convoluted tubule from $5.6 \pm 0.2$ to $6.5 \pm 0.2 \mathrm{~mm}(P$ $<0.005)$. The pattern of $\mathrm{HCO}_{3}^{-}$reabsorption along the length of the proximal convoluted tubule in CMA was indistinguishable from that found in normal rats in which $\mathrm{FL}_{\mathrm{HCO}_{3}}$ was varied acutely by altering SNGFR. The increase in tubular length accounted for only $30 \%$ of the increase in $A P R_{\mathrm{H}_{2} \mathrm{O}}$ and $15 \%$ of the increase in $\mathbf{A P R}_{\mathrm{HCO}_{3}}$. We conclude that a sustained reduction in GFR is not required for maintenance of CMA in the rat. If GFR is chronically restored to normal levels, the alkalosis is maintained by an increase in $\mathbf{A P R} \mathbf{H C O}_{3}$. The increase in reabsorption is accounted for by (1) tubular hypertrophy, a chronic adaptive response, and (2) a load-dependent response that is indistinguishable from that seen in normal rats when $\mathrm{FL}_{\mathrm{HCO}_{3}}$ is increased acutely by increasing SNGFR.
\end{abstract}

\section{Introduction}

Chronic metabolic alkalosis (CMA) ${ }^{1}$ is a disorder in which renal mechanisms sustain an abnormally high plasma bicarbonate

Address correspondence to Dr. Maddox, Division of Nephrology, D305 Given Building. 1985.

Received for publication 15 July 1985 and in revised form 21 October

1. Abbreviations used in this paper: ANF, atrial natriuretic factor; $\mathrm{APR}_{\mathrm{HCO}_{3}}$, absolute proximal reabsorption of bicarbonate; $\mathrm{APR}_{\mathrm{H}_{2} \mathrm{O}}$, absolute proximal water reabsorption; CMA, chronic metabolic alkalosis; ECF, extracellular fluid; $\mathrm{FL}_{\mathrm{HCO}_{3}}$, filtered load of $\mathrm{HCO}_{3}^{-}$; $\mathrm{FPR}_{\mathrm{HCO}_{3}}$, fractional bicarbonate reabsorption in the late proximal tubule; $F_{P R} \mathrm{H}_{2} \mathrm{O}$, fractional water reabsorption in the late proximal tubule; GFR, glomerular filtration rate; SNGFR, single nephron GFR.

J. Clin. Invest.

(c) The American Society for Clinical Investigation, Inc.

0021-9738/86/03/0709/08 $\$ 1.00$

Volume 77, March 1986, 709-716 concentration. Because bicarbonate is freely filtered, an elevated plasma concentration of this anion will result in an increase in filtered bicarbonate unless glomerular filtration rate (GFR) is proportionately reduced. Thus, maintenance of a high plasma bicarbonate concentration requires either a sustained increase in reabsorption in response to the increase in filtered load, or a sustained reduction in GFR. Although an increase in bicarbonate reabsorption has long been assumed to occur in metabolic alkalosis (1), recent studies by Cogan and Liu (2) in rats with mineralocorticoid-induced alkalosis suggest that the high bicarbonate concentration is maintained by a fall in GFR rather than an increase in reabsorption rate. These investigators found that GFR was reduced by $\sim 50 \%$ in rats after induction of CMA. Moreover, when GFR was increased acutely, bicarbonate reabsorption did not increase above control levels. Induction of chloride depletion alkalosis in man, by contrast, results in an increase in renal bicarbonate reabsorption that is apparent within $24 \mathrm{~h}$ despite a small reduction in GFR (3). In a previous study, we found bicarbonate reabsorption to be highly load dependent in rats with chloride depletion alkalosis (4). Our results also suggested that bicarbonate reabsorption could increase above control levels if GFR returned to normal without chloride administration (4). GFR was reduced to $63 \%$ of control values in the first week after induction of alkalosis, but had returned to $83 \%$ of control values, on average, by 11-14 d, without any change in plasma bicarbonate concentration. Thus, renal bicarbonate reabsorption also increased between the first and second week after induction of the alkalosis. Although reabsorption exceeded control values in several animals at 11-14 d, the mean value for the group was not significantly higher than controls. Variations in the filtered load of bicarbonate resulting from differences in single nephron GFR (SNGFR) in these studies were closely associated with parallel changes in proximal tubular bicarbonate reabsorption, indicating that this site in the nephron was an important modulator of overall bicarbonate reabsorption in metabolic alkalosis. By contrast, Cogan and Liu (2) found that proximal bicarbonate reabsorption did not increase when SNGFR was increased acutely in rats with preexisting CMA. One possible explanation for this difference is that the filtered load of bicarbonate in our studies never reached levels sufficient to saturate the transport processes. Because of the low SNGFR values in the strain of rats we studied, proximal bicarbonate reabsorption during metabolic alkalosis never exceeded values seen in normal euvolemic Munich-Wistar rats.

To test whether load dependence of proximal bicarbonate reabsorption extended to higher levels in metabolic alkalosis, we induced this disorder in Munich-Wistar rats using furosemide and dietary chloride restriction, supplemented with $\mathrm{NaHCO}_{3}$. Based on our previous observations (4), we felt it was likely that SNGFR would return to control levels if the rats were studied $>2$ wk after furosemide treatment. Therefore, we studied them between 2 and 4 wk after they received this agent. In these rats, which had stable CMA, GFR (and SNGFR) were not reduced as compared with age-matched control rats, and in response to 
the increase in filtered load, proximal tubular and whole kidney bicarbonate reabsorption increased by $>65 \%$ above control values. Thus, in the rat, renal bicarbonate reabsorption can increase to high levels without evidence of saturation when the filtered load is increased in CMA. A reduction in GFR is not a requirement for maintaining the high plasma bicarbonate concentration in this disorder.

\section{Methods}

All experiments were carried out in male Munich-Wistar rats. (Simonsen Laboratories, Gilroy, CA). Control and experimental animals were placed on a low electrolyte diet (ICN Nutritional Biochemicals, Cleveland, $\mathrm{OH}$ ). For the seven control animals, the diet was supplemented with $2 \mathrm{mmol}$ $\mathrm{NaCl}$ and $1 \mathrm{mmol} \mathrm{KCl} / 12 \mathrm{~g}$. The rats were allowed food and water ad lib., and were studied 2-4 wk after being placed on the diet (mean time on diet, $24 \pm 3 \mathrm{~d}$ ). Metabolic alkalosis was induced in eight age-matched rats by three intraperitoneal injections of furosemide $(10 \mathrm{mg} / \mathrm{kg}$ body weight) given at 12-h intervals 2-3 d after placing them on the low electrolyte diet. In these animals, the diet was supplemented with $2 \mathrm{mmol}$ $\mathrm{NaHCO}_{3}$ and $0.5 \mathrm{mmol} \mathrm{KHCO} 3$ per $12 \mathrm{~g}$. No chloride salts were given. ${ }^{2}$ In addition, $75 \mathrm{mM} \mathrm{NaHCO}$ was given as a drinking solution in place of water up until $24 \mathrm{~h}$ before study. The rats had free access to water during the day before surgery. These animals were studied 2-4 wk after furosemide treatment (mean time from the completion of the furosemide injections to study, $20 \pm 2 \mathrm{~d}$ ). The control and experimental animals were identical in weight at the time they were begun on the diet $(241 \pm 3 \mathrm{~g}$ for CMA, $241 \pm 4 \mathrm{~g}$ for control). At the time of the study, the control rats weighed $272 \pm 3 \mathrm{~g}$. The CMA rats initially lost $12 \pm 2 \mathrm{~g}$ in the first $12-24$ $h$ after completion of the furosemide treatment but returned to a normal growth pattern after the first week, and weighed $251 \pm 2 \mathrm{~g}$ when studied. Because of the weight loss induced by furosemide, the CMA rats weighed significantly less at the time of study than the control rats $(P<0.001)$.

The animals were prepared for micropuncture as described previously (4). They were maintained on a small animal ventilator with added $\mathrm{O}_{2}$ to maintain $\mathrm{PO}_{2}$ at $\sim 100 \mathrm{mmHg}$ (mean $\mathrm{PO}_{2}=106 \mathrm{mmHg}$ in control, $107 \mathrm{mmHg}$ in CMA). The animals were maintained in a euvolemic state by infusion of isoncotic rat plasma ( $1.3 \%$ body weight) as well as a maintenance infusion of ringer solution $(0.84 \mathrm{ml} / \mathrm{h})$ during surgery (5). Subsequently, the rats received a plasma infusion at a rate sufficient to maintain the hematocrit at the level seen immediately after induction of anesthesia and insertion of the femoral artery catheter. At the end of surgery, ${ }^{14} \mathrm{C}$-inulin, $25 \mu \mathrm{Ci}$ in $0.4 \mathrm{ml}$ ringer solution, was given as a bolus, and ${ }^{14} \mathrm{C}$-inulin was added to the maintenance ringer infusion in an amount sufficient to deliver $52 \mu \mathrm{Ci} / \mathrm{h}$. After a 45 -min equilibration period, timed micropuncture collections were obtained from Bowman's space and from

2. The low electrolyte diet contained no inorganic chloride salts, but we discovered that the vitamin mixture used by the ICN Nutritional Biochemicals for both this study and our previous one (4) contained choline chloride. This vitamin additive provided $0.012 \mathrm{mmol}$ chloride $/ \mathrm{g}$ diet, an amount that in theory could lead to eventual correction of the alkalosis. To minimize any likelihood of this occurring, we changed the choline chloride to choline acetate midway through the study. Of the eight rats in which we induced alkalosis, four received the choline chloride, two received only choline acetate, and two were switched from choline chloride to choline acetate after 6 to $7 \mathrm{~d}$ of alkalosis. This dietary change affected plasma bicarbonate concentration notably. In the two rats switched to choline acetate, after 6 or $7 \mathrm{~d}$, mean $\left[\mathrm{HCO}_{3}\right]=40.8 \mathrm{mM}$, while the two rats receiving only choline acetate had a plasma $\left[\mathrm{HCO}_{3}\right]$ of 45.2 and $45.1 \mathrm{mM}$, as compared with $35.3 \pm 1.4 \mathrm{mM}$ in the four rats receiving choline chloride. Despite this effect, the dietary change did not influence SNGFR $(45.8 \pm 1.0$ and $42.7 \pm 2.3 \mathrm{nl} / \mathrm{min}$ in the four rats receiving choline acetate and the four rats receiving choline chloride, respectively) or whole kidney GFR $(1.17 \pm 0.08$ and $1.14 \pm 0.04 \mathrm{ml} / \mathrm{min})$. early, mid, and late proximal tubule sites as described previously $(4,6)$. The puncture sites were marked with a nigrosine-containing saline solution, and the tubules subsequently microdissected. The total length of the proximal convoluted tubule and the distance from the glomerulus to the site of puncture were measured using a calibrated eyepiece micrometer at 72 times magnification. Blood and timed urine samples were collected during the experiment for measurement of arterial $\mathrm{pH}, \mathrm{PCO}_{2}$, $\mathrm{Po}_{2}$, plasma sodium and potassium concentration, urine sodium, potassium and total $\mathrm{CO}_{2}$ excretion, and inulin clearance.

Analytical methods, calculations, and statistics. $\mathrm{Blood} \mathrm{pH}, \mathrm{PCO}_{2}$ and $\mathrm{PO}_{2}$ were measured using a Radiometer blood gas analyzer (Radiometer, Copenhagen, Denmark). Plasma bicarbonate concentration was calculated using the Henderson-Hasselbalch equation. Sodium and potassium concentrations were measured by flame photometry. Plasma protein concentration was measured by refractometry and used for appropriate corrections of plasma inulin concentration. Tubular fluid and urine total $\mathrm{CO}_{2}$ content were measured by microcalorimetry (7). The total $\mathrm{CO}_{2}$ concentration measured in the tubular fluid is assumed to equal the tubular fluid bicarbonate concentration (4). ${ }^{14} \mathrm{C}$-Inulin activity was measured using a liquid scintillation counter. SNGFR and proximal reabsorption rates were calculated using standard formulas. The filtered load of bicarbonate was calculated from the product of SNGFR and Bowman's space bicarbonate concentration. The ratio of Bowman's space bicarbonate concentration to plasma concentration in the alkalotic rats averaged 1.14, a value not significantly different from the value of 1.16 measured in the control rats in this and previous studies $(6,8)$. The relationships between reabsorption and distance from Bowman's space shown in Figs. 2 and 3 were fitted to a power equation of the form $y$ $=a x^{b}$, using a computer-based nonlinear least squares search, as described previously (8). Differences in nonlinear relationships between groups were evaluated by a test of residual sums of squares. Statistical analysis of other results was carried out by paired and unpaired $t$ tests where appropriate. Results are reported as means \pm SE.

\section{Results}

General. Table I presents the arterial blood pressure, experimental hematocrit, plasma composition, and GFR in the control and CMA rats. No significant differences were noted between the two groups in blood pressure, arterial hematocrit, or GFR. Arterial $\mathrm{PCO}_{2}$ in CMA was $45.8 \mathrm{mmHg}$, a value slightly but significantly higher than control, $42.8 \mathrm{mmHg}$. Arterial pH was 7.55 in CMA, as compared with 7.40 in control rats. Mean plasma bicarbonate concentration was significantly increased to $39.1 \mathrm{mM}$, as compared with the control value of $26.0 \mathrm{mM}$. No difference was noted in plasma sodium concentration, but plasma potassium concentration was significantly reduced in CMA, to $2.6 \mathrm{mM}$. Despite the high plasma bicarbonate concentration in the CMA rats, urinary bicarbonate excretion was not different from control; $99.9 \%$ of the filtered bicarbonate was reabsorbed both in CMA and control rats. Urine bicarbonate excretion was $17 \pm 7 \mathrm{nmol} / \mathrm{min}$ in control and $62 \pm 51 \mathrm{nmol} / \mathrm{min}$ in CMA. Urine sodium excretion was not different in the two groups, averaging $392 \pm 137 \mathrm{nmol} / \mathrm{min}$ in control and $456 \pm 175 \mathrm{nmol} / \mathrm{min}$ in CMA. Urine potassium excretion in control animals, $425 \pm 96 \mathrm{nmol} /$ min, was higher than in CMA, $169 \pm 28 \mathrm{nmol} / \mathrm{min}, P<0.025$.

Micropuncture results. Table II summarizes the micropuncture results obtained from late proximal tubular collections. No significant differences were noted in transit time, but SNGFR was significantly higher in CMA than in controls $(44.8 \pm 1.1 \mathrm{nl} /$ $\min$ vs. $38.2 \pm 2.1 \mathrm{nl} / \mathrm{min}, P<0.025$ ). Similar results were obtained when SNGFR values for early and mid as well as late proximal collections were averaged for each animal (43.5 \pm 1.3 $\mathrm{nl} / \mathrm{min}$ in CMA and $37.3 \pm 1.5 \mathrm{nl} / \mathrm{min}$ in controls, $P<0.01)$. As 
Table I. Arterial Blood Composition and Whole Kidney GFR

\begin{tabular}{lllllllll}
\hline Group & $\mathrm{AP}$ & $\mathrm{Hct}$ & $\mathrm{pH}$ & $\mathrm{PCO}_{2}$ & {$\left[\mathrm{HCO}_{3}\right]$} & {$[\mathrm{Na}]$} & $\mathrm{K}]$ & $\mathrm{GFR}$ \\
\hline & $m m H g$ & vol\% & & $m m H g$ & $m M$ & $m M$ & $m M$ & $\mathrm{ml} / \mathrm{min}$ \\
Control $(n=7)$ & $115 \pm 2.5$ & $49.9 \pm 0.4$ & $7.40 \pm 0.01$ & $42.8 \pm 0.3$ & $26.0 \pm 0.4$ & $145.9 \pm 0.6$ & $4.43 \pm 0.03$ & $0.98 \pm 0.10$ \\
CMA $(n=8)$ & $119 \pm 4.8$ & $50.1 \pm 0.9$ & $7.55 \pm 0.01 \ddagger$ & $45.8 \pm 1.8^{*}$ & $39.1 \pm 1.8 \ddagger$ & $145.4 \pm 1.3$ & $2.60 \pm 0.09 \ddagger$ & $1.15 \pm 0.04$
\end{tabular}

$n$, Number of rats; AP, mean arterial blood pressure; Hct, arterial hematocrit; GFR, left kidney inulin clearance. Values shown are mean \pm SE.

$* P<0.05$ compared with control. $¥ P<0.001$ compared with control.

a result of the increase in plasma bicarbonate concentration and SNGFR, the filtered load of bicarbonate $\left(\mathrm{FL}_{\mathrm{HCO}_{3}}\right)$ for the late proximal collections increased markedly from 1,147 to 2,040 $\mathrm{pmol} / \mathrm{min}$. In response to the increase in $\mathrm{FL}_{\mathrm{HCO}_{3}}$, absolute proximal reabsorption of bicarbonate $\left(\mathrm{APR}_{\mathrm{HCO}_{3}}\right)$ increased by $67 \%$ from 970 to $1,624 \mathrm{pmol} / \mathrm{min}$. Fractional bicarbonate reabsorption in the late proximal tubule $\left(\mathrm{FPR}_{\mathrm{HCO}_{3}}\right)$ was unchanged, averaging 0.84 in controls and 0.80 in CMA. Water reabsorption by the proximal tubule $\left(\mathrm{APR}_{\mathrm{H}_{2} \mathrm{O}}\right)$ also increased significantly, from 18.4 to $24.9 \mathrm{nl} / \mathrm{min}$. As a result, the fraction of filtered water reabsorbed in the proximal tubule increased from 0.48 to 0.56 . The concentration of bicarbonate in the late proximal tubule was $20.7 \pm 1.1 \mathrm{mM}$ in CMA as compared with $8.1 \pm 0.9 \mathrm{mM}$ in control, $P<0.001$. Fig. 1 shows plasma bicarbonate concentration, and SNGFR, GFR, whole kidney $\mathrm{HCO}_{3}^{-}$reabsorption, and $\mathrm{APR}_{\mathrm{HCO}_{3}}$ as a percentage of control values for both the present study and our previous study (4). SNGFR, GFR, whole kidney $\mathrm{HCO}_{3}^{-}$reabsorption, and $\mathrm{APR}_{\mathrm{HCO}_{3}}$ were below normal 4-7 d postfurosemide. With time, however, all values returned to or above control, while maintaining the alkalosis.

Renal hypertrophy. Despite the fact that the CMA rats weighed less than the control animals, whole kidney weight was greater, $1.18 \pm 0.04 \mathrm{~g}$, as compared with control, $1.01 \pm 0.02 \mathrm{~g}, P$ $<0.005$. The hypertrophy was evident as well for the proximal tubule. The distance from the glomerulus to the end of the proximal convoluted tubule was $6.5 \pm 0.2 \mathrm{~mm}$ in 29 tubules dissected and measured in the eight CMA rats. This value was significantly longer than the value measured in 14 proximal convoluted tubules in six control rats, $5.6 \pm 0.2 \mathrm{~mm}, P<0.005$.

Pattern of bicarbonate reabsorption along the tubule. In Fig. 2 we have plotted bicarbonate reabsorption as a function of distance from the glomerulus to the site of collection in rats with comparable filtered loads. For this assessment, we have grouped our observations over three ranges of $\mathrm{FL}_{\mathrm{HCO}_{3}}$ which include all the values obtained in the CMA rats: $1,200-1,600,1,600-2,000$, and $>2,000 \mathrm{pmol} / \mathrm{min}$. Each point shown in the figure represents a single tubular fluid collection (closed triangles, age-matched control rats; closed circles and squares, CMA rats). For the two lower ranges of $\mathrm{FL}_{\mathrm{HCO}_{3}}$, we include for comparison the $95 \%$ confidence bands (shaded regions) for the relationship found in normal rats in which $\mathrm{FL}_{\mathrm{HCO}_{3}}$ was varied acutely by changes in SNGFR induced by hydropenia, euvolemia, plasma expansion, or aortic constriction (8). For the highest range, only two data points from the previous study (8) are available for comparison (open circles). The specific nonlinear regression equations for these data are given in Table III. The majority of the present observations in CMA were made in rats with $\mathrm{FL}_{\mathrm{HCO}_{3}}$ values of either $1,600-2,000$ or $>2,000 \mathrm{pmol} / \mathrm{min}$. In the $1,600-2,000$ $\mathrm{pmol} / \mathrm{min}$ range, no significant difference was noted in the relationship between $\mathrm{APR}_{\mathrm{HCO}_{3}}$ and distance from the glomerulus in CMA as compared with normal rats with acute variations in $\mathrm{FL}_{\mathrm{HCO}_{3}}$. In all settings, the majority of the bicarbonate reabsorbed is recaptured in the first $2 \mathrm{~mm}$ of the tubule. In the lower range $\left(\mathrm{FL}_{\mathrm{HCO}_{3}}=1,200-1,600 \mathrm{pmol} / \mathrm{min}\right)$, three of the six values for CMA fell below the confidence bands, and the metabolic alkalosis relationship differed significantly from normal $(P<0.05$, Table III). However, all three of these points are from the same animal, as are two out of four of the points in the middle panel that fall below the confidence bands (values from this animal are denoted by closed squares). This animal had a lower fractional reabsorption at all points along the nephron than did the seven other rats with metabolic alkalosis (denoted by closed circles). At the highest range of filtered bicarbonate, the pattern of reabsorption along the tubule is similar to that observed at the lower ranges; $60-70 \%$ is recaptured in the first $2 \mathrm{~mm}$, and there is no evidence of saturation.

Pattern of fluid reabsorption along the tubule. In Fig. 3, we have plotted $A P R_{\mathrm{H}_{2} \mathrm{O}}$ against distance from the glomerulus for CMA (closed circles) and control (closed triangles) rats with comparable SNGFR values. For this assessment, we grouped our observations over two ranges, SNGFR values of 30-45 nl/ min and SNGFR values of $45-60 \mathrm{nl} / \mathrm{min}$. As in the previous figure, we have included the $95 \%$ confidence bands (shaded area) for $A P R_{\mathrm{H}_{2} \mathrm{O}}$ vs. distance for a large group of normal rats with SNGFR values in either the $30-45-$ or $45-60-\mathrm{nl} / \mathrm{min}$ ranges reported previously (8). The equations derived from the normal

Table II. Single Nephron Function and Proximal Reabsorption*

\begin{tabular}{|c|c|c|c|c|c|c|c|}
\hline Group & SNGFR & $\mathrm{APR}_{\mathrm{H}>\mathrm{O}}$ & $\mathrm{FPR}_{\mathrm{H}>\mathrm{O}}$ & $\mathrm{FL}_{\text {HCOS }}$ & $\mathbf{A P R}_{\text {HCOS }}$ & $\mathrm{FPR}_{\mathrm{HCO}}$ & TT \\
\hline & $\mathrm{nl} / \mathrm{min}$ & $n l / m i n$ & & $\mathrm{pmol} / \mathrm{min}$ & $\mathrm{pmol} / \mathrm{min}$ & & $s$ \\
\hline Control $(n=7)$ & $38.2 \pm 2.1$ & $18.4 \pm 1.6$ & $0.48 \pm 0.02$ & $1,147 \pm 61$ & $970 \pm 65$ & $0.84 \pm 0.02$ & $9.2 \pm 0.7$ \\
\hline CMA $(n=8)$ & $44.8 \pm 1.1 \mp$ & $24.9 \pm 0.8 \S$ & $0.56 \pm 0.02 \ddagger$ & $2,040 \pm 109^{\prime \prime}$ & $1,624 \pm 86^{\prime \prime}$ & $0.80 \pm 0.01$ & $9.4 \pm 0.9$ \\
\hline
\end{tabular}

$n$, Number of rats. TT, lissamine green transit time to the end of the proximal convoluted tubule. * Results obtained from end-proximal collections. $\ddagger P<0.025$. $\S P<0.005$. " $P<0.001$, as compared with control. 


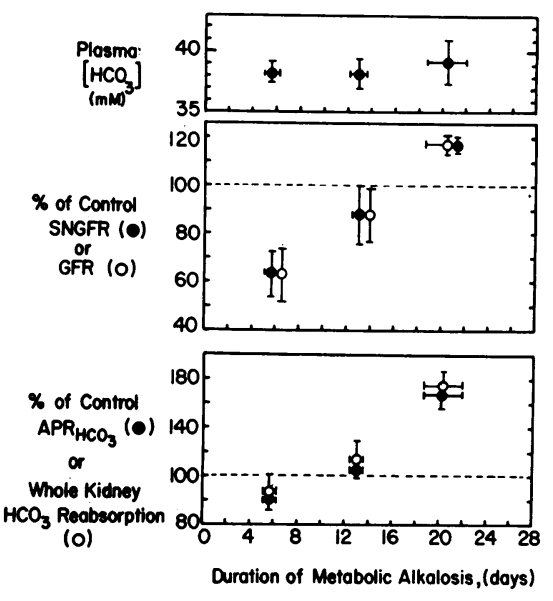

Figure 1. Plasma $\left[\mathrm{HCO}_{3}\right], \mathrm{GFR}$, and bicarbonate reabsorption as a function of the duration of metabolic alkalosis. Whole kidney GFR and SNGFR are expressed as a percentage of control values obtained in age-matched rats studied concurrently. Absolute proximal bicarbonate reabsorption $\left(\mathrm{APR}_{\mathrm{HCO}_{3}}\right)$ and whole kidney bicarbonate reabsorption are also expressed as a percentage of control values. The data shown at 4-7 and 11-14 d of alkalosis are from a previous study (4).

and CMA data are compared in Table III. As can be seen in Fig. 3, no differences in the pattern of fluid reabsorption were present among these groups. However, because of the extra 1 mm of tubule length in the CMA rats, together with the higher SNGFR, more fluid was reabsorbed to the end of the proximal tubule than in the age-matched control animals ( 24.9 vs. 18.4

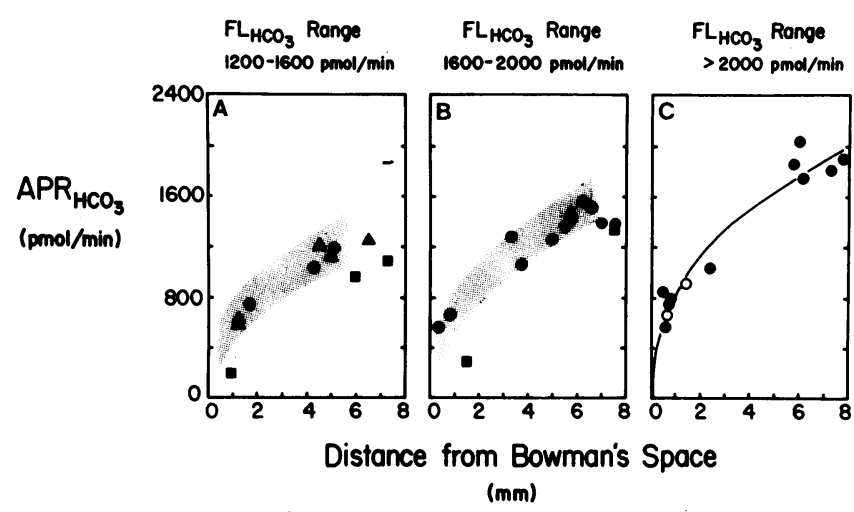

Figure 2. $\mathrm{APR}_{\mathrm{HCO}_{3}}$ as a function of distance from Bowman's space in millimeters. Data are subdivided into three groups according to the filtered load of bicarbonate $\left(\mathrm{FL}_{\mathrm{HCO}_{3}}\right): \mathrm{FL}_{\mathrm{HCO}_{3}}=1,200-1,600 \mathrm{pmol} / \mathrm{min}$; $\mathrm{FL}_{\mathrm{HCO}_{3}}=1,600-2,000 \mathrm{pmol} / \mathrm{min}$; and $\mathrm{FL}_{\mathrm{HCO}_{3}}=>2,000 \mathrm{pmol} / \mathrm{min}$. In $A$ and $B$ the solid triangles are data from age-matched control rats, the solid circles and squares are CMA rats, and the shaded area denotes the $95 \%$ confidence bands for a group of normal rats studied previously (8) in which $\mathrm{FL}_{\mathrm{HCO}_{3}}$ was varied acutely by altering SNGFR. The solid squares in $A$ and $B$ are data from one rat in which all values fell below the $95 \%$ confidence bands of the data from normal rats. The solid circles on all panels denote the data from the remaining seven CMA rats. For $C$, insufficient data from the normal rats studied previously (8) are available to generate a confidence band. The two points that were obtained in this range of $\mathrm{FL}_{\mathrm{HCO}_{3}}$ in normal rats are denoted by open circles. The line in $C$ depicts the best fit for data from the normal and CMA rats combined (see Table III). $\mathrm{nl} / \mathrm{min}$, Table II), thereby increasing the fraction of filtered water reabsorbed along the tubule from 0.48 to 0.56 .

\section{Discussion}

The present studies demonstrate that a sustained reduction in GFR is not required to maintain CMA. As shown in Fig. 1, GFR and SNGFR varied from 63 to $117 \%$ of control values as a function of time after furosemide treatment in our model of metabolic alkalosis, with no change in plasma bicarbonate concentration. As shown in this figure, depending on the GFR, proximal tubule and whole kidney bicarbonate reabsorption were less than, equal to, or significantly greater than control values. In contrast to our results, Cogan and Liu (2) found GFR to be only $60 \%$ of control values $11-14 \mathrm{~d}$ after inducing metabolic alkalosis with desoxycorticosterone acetate and sodium sulfate administration. As a result, bicarbonate reabsorption never increased above control levels. The difference in GFR in these two models of metabolic alkalosis remains unexplained. Our studies indicate that a major reduction in GFR is not an inherent feature of metabolic alkalosis. Thus, some other explanation must be sought. The model induced by Cogan and Liu (2) is clearly associated with volume contraction; plasma volume fell by $28 \%$. This reduction in plasma volume was probably due to the continued administration of the diuretic agent, sodium sulfate, throughout the period of study. Such a reduction in plasma volume could certainly account for the reduction in GFR. Our rats were presumably also volume contracted by furosemide, since they lost an average $12 \mathrm{~g}$ in weight after diuretic treatment. After this treatment, however, no diuretic was administered and excess electrolyte in the form of sodium and potassium bicarbonate was given, providing a substrate for potential repletion of extracellular fluid (ECF) volume. In our previous study (4), the volume loss induced by furosemide was not fully repaired at 4-7 d, and GFR was $60 \%$ of control (Fig. 1). In rats studied for a longer time, the weight loss was recovered, additional growth occurred, and GFR returned to near normal levels (4). No measurements of plasma volume were carried out in our earlier study or in the present study, and therefore we cannot exclude continued plasma volume contraction. However, a marked reduction in plasma or ECF volume in the present study seems unlikely, since GFR and SNGFR were at or above normal levels.

In CMA rats receiving no chloride, repletion and growthrelated increases in plasma and ECF volume can only occur if $\mathrm{NaHCO}_{3}$ is retained. One can estimate the influence on plasma bicarbonate concentration of ECF volume repletion with sodium bicarbonate. This estimation is based on a bicarbonate space of distribution of $45 \%$ body weight (9), on the assumption that furosemide induces no net bicarbonate losses (10), and that no chloride is ingested after furosemide treatment. The latter assumption only pertained in two of our rats. ${ }^{2}$ These rats had an average plasma bicarbonate concentration of $45.2 \mathrm{mM}$ at the time of study. Given our assumptions concerning furosemide, one would anticipate plasma bicarbonate concentration to increase from 26 to $29 \mathrm{mM}$ after a $12-\mathrm{g}(\mathrm{ml})$ furosemide-induced ECF volume loss. Repletion of this loss entirely with isotonic $(\sim 150 \mathrm{mM}) \mathrm{NaHCO}_{3}$ would result in a plasma bicarbonate concentration of $42.4 \mathrm{mM}$. These two rats had an additional weight gain of $5.5 \mathrm{~g}$ above their prefurosemide weight $(246 \mathrm{~g})$. Assuming that bicarbonate is distributed in $45 \%$ of this weight gain, then continued ECF volume repletion with isotonic bi- 


\begin{tabular}{|c|c|c|c|c|c|c|c|c|}
\hline \multirow[b]{2}{*}{ Filtered load range } & \multirow[b]{2}{*}{ Group } & \multicolumn{2}{|c|}{ Coefficients* } & \multirow[b]{2}{*}{$r$} & \multirow[b]{2}{*}{$n$} & \multirow[b]{2}{*}{$F$} & \multirow[b]{2}{*}{ SNGFR } & \multirow[b]{2}{*}{$\mathrm{FL}_{\text {HoOs }}$} \\
\hline & & A & B & & & & & \\
\hline & & & & & & & $n l / \min$ & pmol/min \\
\hline \multirow{2}{*}{ 1. SNGFR, $30-45 \mathrm{nl} / \mathrm{min}$} & Normal & 6.71 & 0.62 & 0.928 & 43 & \multirow{2}{*}{0.06} & $37.1 \pm 0.5$ & - \\
\hline & CMA & 6.69 & 0.62 & 0.935 & 18 & & $39.7 \pm 0.9 \S$ & - \\
\hline \multirow{2}{*}{ 2. SNGFR, $45-60 \mathrm{nl} / \mathrm{min}$} & Normal & 8.90 & 0.56 & 0.984 & 17 & \multirow{2}{*}{1.71} & $50.6 \pm 1.2$ & - \\
\hline & CMA & 10.72 & 0.47 & 0.950 & 11 & & $48.6 \pm 1.0$ & - \\
\hline \multirow{2}{*}{ 3. $\mathrm{FL}_{\mathrm{HCO}_{3}}, 1,200-1,600 \mathrm{pmol} / \mathrm{min}$} & Normal & 600 & 0.43 & 0.956 & 23 & \multirow{2}{*}{$5.14 \S$} & - & $1,384 \pm 23$ \\
\hline & CMA & 460 & 0.48 & 0.862 & 6 & & - & $1,430 \pm 30$ \\
\hline \multirow{2}{*}{ 4. $\mathrm{FL}_{\mathrm{HCO}_{3}}, 1,600-2,000 \mathrm{pmol} / \mathrm{min}$} & Normal & 670 & 0.44 & 0.986 & 11 & \multirow{2}{*}{0.74} & - & $1,776 \pm 34$ \\
\hline & CMA & 600 & 0.46 & 0.870 & 13 & & - & $1,765 \pm 28$ \\
\hline 5. $\mathrm{FL}_{\mathrm{HCO}_{3}},>2,000 \mathrm{pmol} / \mathrm{min}$ & $\begin{array}{l}\text { Combined normal } \\
+ \text { CMA }\end{array}$ & 850 & 0.41 & 0.968 & 12 & - & - & $2,252 \pm 50$ \\
\hline
\end{tabular}

$r$, Correlation coefficient; $n$, number of observations; $F$, variance ratio. SNGFR and $\mathrm{FL}_{\mathrm{HCO}_{3}}$, mean values for single nephron glomerular filtration rate and the filtered load of bicarbonate for the data used to generate the curves. ${ }^{*}$ Coefficients $A$ and $B$ for the equation $y=A(D)^{B}$ where $D$ $=$ distance from Bowman's space in millimeters and $y=$ absolute proximal reabsorption of water $(1$ and 2$)$ or bicarbonate $(3,4$, and 5). $\ddagger$ Data for normal rats obtained from previous study in which SNGFR and $\mathrm{FL}_{\mathrm{HCO}_{3}}$ were varied acutely $(8) . \quad \S P<0.05$ vs. normal rats.

carbonate would produce a final plasma bicarbonate concentration of $44.6 \mathrm{mM}$. Based on this computation and the observed plasma bicarbonate concentration in these two rats, it appears likely that ECF volume was restored by avid sodium bicarbonate reabsorption. Alternatively, it is possible that the increase in GFR with time is unrelated to ECF volume, but is due to some influence of renal hypertrophy on glomerular function. This possibility cannot be excluded, but it seems unlikely. Although hypokalemia stimulates renal hypertrophy $(11,12)$, this treatment is also known to reduce rather than increase GFR (2). GFR levels in our rats, therefore, cannot be accounted for by any effect of potassium depletion on the kidney.

In our studies, SNGFR and whole kidney GFR were closely

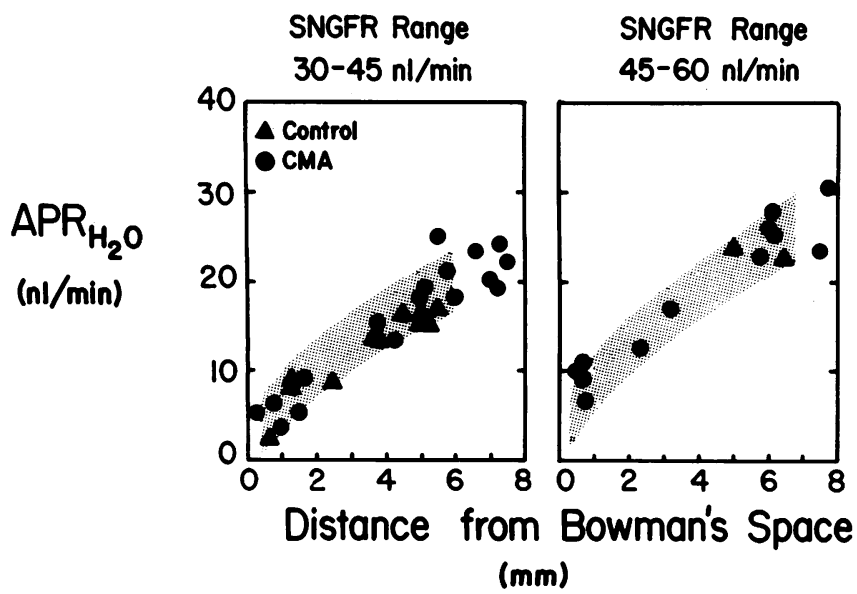

Figure 3. $\mathrm{APR}_{\mathrm{H}_{2} \mathrm{O}}$ as a function of distance from Bowman's space in millimeters. Data are subdivided into two groups, those with SNGFR values of 30-45 $\mathrm{nl} / \mathrm{min}$, and those with SNGFR values of 45-60 nl/ min. The solid circles are data from CMA rats and the solid triangles are data from age-matched control rats. The shaded areas denote the 95\% confidence bands for $\mathrm{APR}_{\mathrm{H}_{2} \mathrm{O}}$ in a group of normal rats studied previously (8) in which SNGFR was varied acutely. See Table III for regression equations and statistical comparisons. correlated (Fig. 1). These results contrast with the findings of in which chloride depletion was induced by peritoneal dialysis. In their study, SNGFR measured at late proximal tubular sites was not reduced in rats with metabolic alkalosis as compared with control. However, SNGFR measured at early distal tubular sites was reduced significantly, and the reduction in distal SNGFR correlated with changes in whole kidney GFR. These workers postulated that chloride depletion heightened glomerulotubular feedback, thereby reducing GFR in metabolic alkalosis. Interruption of flow during proximal tubular collections prevented the feedback signal, and thus SNGFR returned to normal levels. Although acute chloride depletion metabolic alkalosis may depress GFR in this manner, we could find no evidence for such an effect in chronic metabolic alkalosis. In neither our previous (4) nor present study was SNGFR (measured at the late proximal tubule) disproportionately higher than whole kidney GFR, when considered as a percentage of control (Fig. 1). Changes in SNGFR in both studies were reflected by parallel changes in whole kidney GFR. In addition, no difference was noted in SNGFR between collections made in the late proximal tubule or early distal tubule in two rats in the present study.

Our results indicate that proximal tubular bicarbonate reabsorption in CMA varies directly in relation to variations in the filtered load. Fig. 4 shows this relationship both for the present study (open circles) and for our previous study (reference 4, open squares). The rats in these two studies had equally high plasma bicarbonate concentrations, and thus the differences in

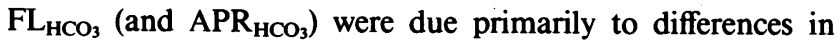
SNGFR. There is no evidence for saturation of bicarbonate reabsorptive capacity over the entire range of filtered loads in the two studies, $300-2,500 \mathrm{pmol} / \mathrm{min}$. The mean values for the control Munich-Wistar rats in the present study (open hexagon) and in a previous study (open diamond [14]) are shown for comparison. It is evident that all the values for $\mathrm{FL}_{\mathrm{HCO}_{3}}$ and $\mathrm{APR}_{\mathrm{HCO}_{3}}$ in the CMA rats in the present study are greater than the mean values found in these two control Munich-Wistar groups. In addition, all the values in the present study are greater than the mean value obtained in CMA by Cogan and Liu ([2], 


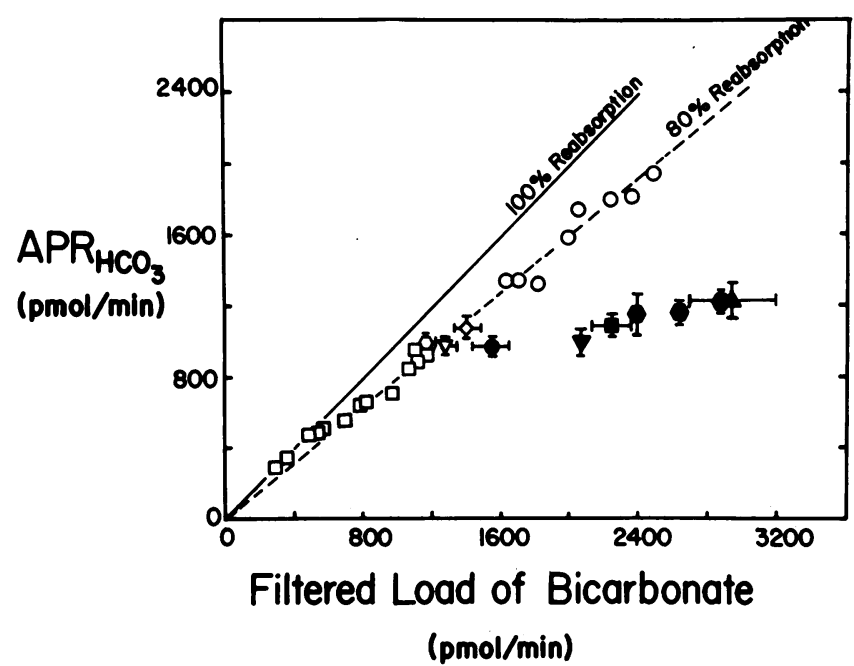

Figure 4. Absolute bicarbonate reabsorption measured at late proximal tubular sites as a function of the filtered load. Open circles denote rats with CMA from the present study; open squares are CMA rats from our previous study (4). The open hexagon and open diamond denote mean control values from the present and a previous (14) study, respectively, while the open inverted triangle represents the mean value for CMA rats from the study of Cogan and Liu (2). The filled circle denotes CMA rats acutely volume expanded with colloidfree, isohydric solutions (2). The filled inverted triangle represents acute, volume expansion metabolic alkalosis (AMA) from reference 16 , the filled square denotes AMA rats from reference 2, the filled hexagons are from AMA rats from reference 15 , and the filled triangle is from AMA rats (15) in which arterial $\mathrm{pH}$ was acutely restored to normal with hypercapnia.

inverted open triangle). It is noteworthy, however, that their mean value falls on the same line as do all our observations, indicating a fractional reabsorption of $\sim 80 \%$. The major difference between their study and the present one, therefore, is that their SNGFR values were lower. In contrast to all these observations are the seven additional settings shown in the figure in which $\mathrm{FL}_{\mathrm{HCO}_{3}}$ in alkalotic rats was increased acutely in association with ECF volume expansion. The filled circle shows the mean response in CMA rats to acute ECF volume expansion (7-10\% body weight) with isohydric ringer solution (2). The response of normal rats to acute sodium bicarbonate loading (7$10 \%$ body weight of either 150 or $200 \mathrm{mM}$ bicarbonate solutions) is shown by the filled square (2), the filled hexagons (15), and the inverted filled triangle (16).

One possible explanation for the difference between these acute studies and all the chronic studies is that the proximal tubule requires prolonged exposure to a sustained increase in $\mathrm{FL}_{\mathrm{HCO}_{3}}$ in order to increase its reabsorptive capacity above control values. Evidence for such a chronic adaptive response is our finding that the length of the proximal convoluted tubule increased significantly in the CMA rats. The equations relating $\mathrm{APR}_{\mathrm{HCO}_{3}}$ to distance from Bowman's space (Table III) were used to calculate the contribution of this increase in tubular length (from 5.6 to $6.5 \mathrm{~mm}$ ) to proximal reabsorption. Regardless of the range of filtered loads used, the longer (CMA length) tubule was calculated to reabsorb $\sim 100 \mathrm{pmol} / \mathrm{min}$ more than the shorter control length tubule. This calculated difference, however, only accounts for $15 \%$ of the mean difference in $\mathrm{APR}_{\mathrm{HCO}_{3}}$ be-

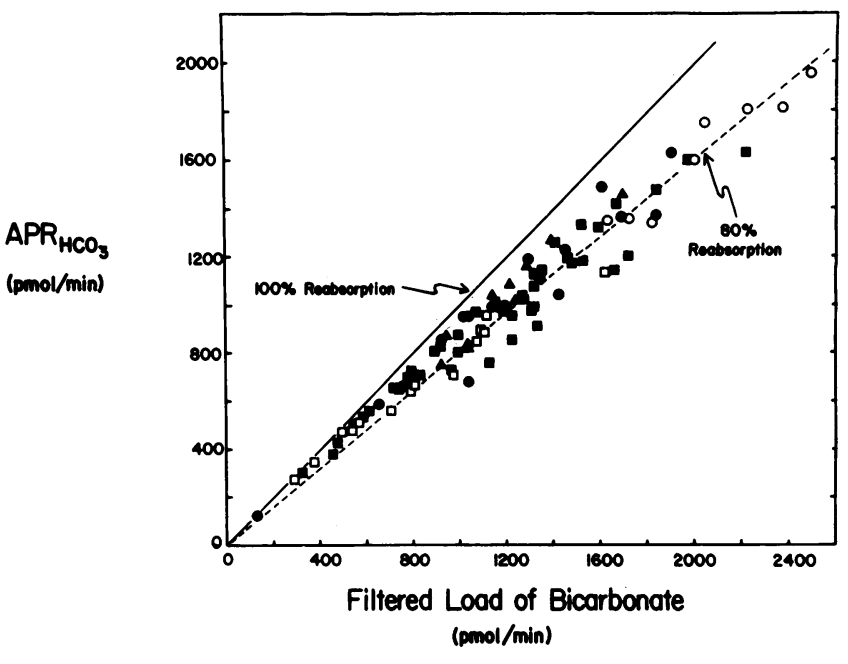

Figure 5. Absolute bicarbonate reabsorption measured at late proximal tubular sites $\left(\mathrm{APR}_{\mathrm{HCO}_{3}}\right)$ as a function of the filtered load. Open circles denote rats with CMA from the present study and open squares from a previous study (4). The closed triangles are from age-matched control rats in the present study. The closed circles are data from normal rats in which SNGFR was varied acutely by hydropenia, euvolemia, isoncotic plasma expansion, and aortic constriction (8), while the filled squares are similarly treated normal rats from reference 14 . The data from reference 14 are not corrected for kidney weight (as they originally were in reference 14) to coincide with the manner in which the other data are presented.

tween control and CMA (654 pmol/min). ${ }^{3}$ The major component of the increase is related directly to the increase in $\mathrm{FL}_{\mathrm{HCO}_{3}}$. This effect is illustrated in Fig. 5. In this figure, we have plotted the relationship between $\mathrm{FL}_{\mathrm{HCO}_{3}}$ and $\mathrm{APR}_{\mathrm{HCO}_{3}}$ not only in control and CMA rats, but also in normal rats in which $\mathrm{FL}_{\mathrm{HCO}_{3}}$ was varied acutely by hydropenia, euvolemia, isoncotic plasma expansion, or aortic constriction $(8,14)$. As can be seen, no major differences in fractional reabsorption are present between the CMA rats and these acute studies, even at filtered loads as high as $2,200 \mathrm{pmol} / \mathrm{min}$. Thus, it appears that proximal bicarbonate reabsorption can increase acutely after abrupt increases in $\mathrm{FL}_{\mathrm{HCO}_{3}}$ in a manner that is indistinguishable from the response after chronic increases in $\mathrm{FL}_{\mathrm{HCO}_{3}}$. The acute changes were induced over $1-2 \mathrm{~h}$.

The reason for the lower fractional proximal bicarbonate reabsorption after acute treatment with colloid-free ECF volume expanding solutions (filled symbols in Fig. 4) remains obscure. Acute isohydric expansion in normal animals has little effect on proximal bicarbonate reabsorption $(14,17,18)$. If acute volume expansion is coupled with alkalemia, however, fractional bicarbonate reabsorption falls dramatically $(2,15,16)$, an effect which,

3. This estimate assumes that the increased tubule reabsorptive surface has late proximal reabsorptive characteristics, as is suggested by the anatomic observations of Oliver and co-workers $(11,12)$ in chronic potassium and chloride depletion alkalosis. Further support for this assumption is the concordance between the control and CMA data shown in Fig. 2. Our observations, however, cannot exclude the possibility that this concordance is the fortuitous result of inhibition of reabsorption by alkalemia and stimulation of reabsorption by selective addition of early proximal type reabsorptive surface. 
as shown by the filled triangle in Fig. 4, cannot be reversed acutely by restoring $\mathrm{pH}$ to normal (15). An intriguing recent observation is that atrial natriuretic factor (ANF), without volume expansion, produces a similar response. In normal animals, absolute bicarbonate reabsorption increases in a normal load-dependent fashion after ANF-induced increases in SNGFR (19). However, in animals with CMA, increases in SNGFR brought about by ANF administration are not accompanied by significant increases in $\mathrm{APR}_{\mathrm{HCO}_{3}}(20)$, mimicking the response seen when alkalosis and volume expansion are combined (Fig. 4). Since ANF is released after volume expansion (21), it is conceivable that this hormone plays a role in the difference in response between CMA rats and acutely expanded alkalemic rats.

The present studies were not designed to determine the mechanisms by which proximal bicarbonate reabsorption can increase above control values in CMA. The hypokalemia that invariably accompanies sustained metabolic alkalosis has been implicated as a factor stimulating proximal bicarbonate reabsorption (22). However, we and others $(2,4)$ have found no difference in the relationship between filtered load and proximal bicarbonate reabsorption between normokalemic and hypokalemic (CMA) rats (e.g., Fig. 5). Thus, either hypokalemia has an insignificant effect, or its effect to stimulate reabsorption is precisely counterbalanced by the effect of alkalemia to blunt reabsorption. Our observations do not allow us to choose between these possibilities. Recent observations suggest other mechanisms to account for changes in proximal reabsorptive capacity. Schwartz and Al-Awqati (23) have recently shown that vesicles containing hydrogen ion translocating pumps appear to insert into the apical membrane of the proximal straight tubule within $1 \mathrm{~min}$ of exposure to an elevation in $\mathrm{PCO}_{2}$ and an increase in luminal bicarbonate delivery. Enhanced sodium-hydrogen exchange activity has also been shown to occur in brush border membrane vesicles within $24 \mathrm{~h}$ of uninephrectomy (24). The increase in exchange activity in these studies correlated directly with the change in GFR, and thus with the increase in filtered bicarbonate load induced. These results suggest that alterations in membrane hydrogen ion transporter number or activity can occur rapidly in response to increased $\mathrm{FL}_{\mathrm{HCO}_{3}}$. Whether such changes are actually responsible for the increase in proximal bicarbonate reabsorption seen acutely with plasma expansion or chronically in metabolic alkalosis remains to be determined.

Proximal tubular fluid reabsorption also increased substantially in metabolic alkalosis as compared to control. As in the case of bicarbonate, this increase in reabsorption is due in part to the increase in filtered load (SNGFR) and in part to the increase in tubule length. Using the equations relating fluid reabsorption to length along the tubule (Table III), $\sim 30 \%$ of the increase in water reabsorption can be accounted for by the increase in tubule length. The remainder is a load-dependent increase indistinguishable from that seen in normal rats in which SNGFR is increased acutely. Since the pattern of fluid reabsorption along the proximal tubule, for any given filtered load, was not different from that seen in normal rats (Fig. 3), it is apparent that the increase in fractional reabsorption in the CMA rats is largely due to the increase in tubule length.

In summary, these studies indicate that maintenance of metabolic alkalosis in the rat does not require a sustained reduction in GFR. If GFR is restored to control levels without chloride administration, proximal tubular and whole kidney bicarbonate reabsorption increase to levels significantly higher than control in response to the high filtered load. Two factors appear to contribute to the high proximal bicarbonate reabsorptive rate seen in metabolic alkalosis. The first is an adaptive increase in proximal tubular length, which increases reabsorptive surface area. This change is not seen in acute loading studies, and accounts for some $15 \%$ of the increase in reabsorption. The second factor appears to be a response of overall tubular bicarbonate transport to the increase in $\mathrm{FL}_{\mathrm{HCO}_{3}}$. This latter factor in chronic metabolic alkalosis is indistinguishable from the tubular response to acute increases in $\mathrm{FL}_{\mathrm{HCO}_{3}}$ in normal rats, and accounts for the majority of the increase in proximal reabsorption. Whether the mechanisms responsible for inducing both these acute and chronic changes in proximal bicarbonate reabsorption are the same remains to be determined.

\section{Acknowledgments}

The authors are grateful to William D. Barnes and Vidya Gadamasetti for expert technical assistance, and to Donna C. Bryan for preparation of this manuscript. This work was supported by National Institutes of Health (NIH) grants AM 26699 and AM30872.

Dr. Maddox is the recipient of Research Career Development Award 1-KO4-AM-01057 from the NIH.

\section{References}

1. Kassirer, J. P., and W. B. Schwartz. 1965. The response in normal man to selective depletion of hydrochloric acid. Am. J. Med. 40:10-18.

2. Cogan, M. G., and F. Y. Liu. 1983. Metabolic alkalosis in the rat. Evidence that reduced glomerular filtration rather than enhanced tubular bicarbonate reabsorption is responsible for maintaining the alkalotic state. J. Clin. Invest. 71:1141-1160.

3. Berger, B. E., M. G. Cogan, and A. Sebastian. 1984. Reduced glomerular filtration and enhanced bicarbonate reabsorption maintain metabolic alkalosis in humans. Kidney Int. 26:205-208.

4. Maddox, D. A., and F. J. Gennari. 1983. Proximal tubular bicarbonate reabsorption and $\mathrm{PCO}_{2}$ in chronic metabolic alkalosis in the rat. J. Clin. Invest. 72:1385-1395.

5. Maddox, D. A., D. C. Price, and F. C. Rector, Jr. 1977. Effects of surgery on plasma volume and salt and water excretion in rats. Am. J. Physiol. 233(Renal Fluid and Electrolyte Physiol. 2):F600-F606.

6. Maddox, D. A., L. J. Atherton, W. M. Deen, and F. J. Gennari. 1984. Proximal $\mathrm{HCO}_{3}^{-}$reabsorption and the determinants of tubular and capillary $\mathrm{PCO}_{2}$ in the rat. Am. J. Physiol. 247(Renal Fluid Electrolyte Physiol. 16):F73-F81.

7. Vurek, G. G., D. G. Warnock, and R. Corsey. 1975. Measurement of picomole amounts of carbon dioxide by calorimetry. Anal. Chem. 47: 765-767.

8. Maddox, D. A., and F. J. Gennari. 1985. Load dependence of $\mathrm{HCO}_{3}$ and $\mathrm{H}_{2} \mathrm{O}$ reabsorption in the early proximal tubule of the MunichWistar rat. Am. J. Physiol. 248(Renal Fluid Electrolyte Physiol. 17): F113-F121.

9. Adrogué, H. J., J. Brensilver, J. J. Cohen, and N. E. Madias. 1983. Influence of steady state alterations in acid-base equilibrium on the fate of administered bicarbonate in the dog. J. Clin. Invest. 71:867-883.

10. Hropot, M., N. Fowler, B. Karlmark, and G. Giebisch. 1985. Tubular action of diuretics: distal effects on electrolyte transport and acidification. Kidney Int. 28:477-489.

11. Oliver, J., M. MacDowell, L. G. Welt, M. A. Holliday, W. Hollander, Jr., R. W. Winters, T. F. Williams, and W. E. Segar. 1957. The renal lesions of electrolyte imbalance. I. J. Expt. Med. 106:563-574.

12. Holliday, M. A., N. H. Bright, D. Schultz, and J. Oliver. 1961. The renal lesions of electrolyte imbalance. III. J. Exp. Med. 113:971980.

13. Galla, J. H., D. M. Bonduris, P. W. Sanders, and R. G. Luke. 
1984. Volume-independent reduction in glomerular filtration rate in acute chloride-depletion alkalosis in the rat. J. Clin. Invest. 74:2002-2008.

14. Cogan, M. G., D. A. Maddox, M. S. Lucci, and F. C. Rector, Jr. 1979. Control of proximal bicarbonate reabsorption in normal and acidotic rats. J. Clin. Invest. 64:1168-1180.

15. Cogan, M. G. 1984. Effects of acute alterations in $\mathrm{PCO}_{2}$ on proximal $\mathrm{HCO}_{3}^{-}, \mathrm{Cl}^{-}$, and $\mathrm{H}_{2} \mathrm{O}$ reabsorption. Am. J. Physiol. 246(Renal Fluid Electrolyte Physiol. 15):F21-F26.

16. Cogan, M. G. 1984. Chronic hypercapnia stimulates proximal bicarbonate reabsorption in the rat. J. Clin. Invest. 74:1942-1947.

17. Cogan, M. G. 1983. Volume expansion predominantly inhibits proximal reabsorption of $\mathrm{NaCl}$ rather than $\mathrm{NaHCO}_{3}$. Am. J. Physiol. 245(Renal Fluid Electrolyte Physiol. 14):F272-F275.

18. Alpern, R. J., M. G. Cogan, and F. C. Rector, Jr. 1983. Effects of extracellular fluid volume and plasma bicarbonate concentration on proximal acidification in the rat. J. Clin. Invest. 71:736-746.

19. Huang, C.-L., J. Lewicki, L. K. Johnson, and M. G. Cogan. 1985.
Renal mechanism of action of rat atrial natriuretic factor. J. Clin. Invest. 75:769-773.

20. Cogan, M. G. 1985. Atrial natriuretic factor ameliorates chronic metabolic alkalosis by increasing glomerular filtration rate. Science (Wash. DC). 229:1405-1407.

21. Pettersson, A., S. E. Ricksten, A. C. Towle, J. Hedner, and T. Hedner. 1985. Effect of blood volume expansion and sympathetic denervation on plasma levels of atrial natriuretic factor (ANF) in the rat. Acta Physiol. Scand. 124:309-311.

22. Chan, Y. L., B. Biagi, and G. Giebisch. 1982. Control mechanism of bicarbonate transport across the rat proximal convoluted tubule. Am. J. Physiol. 242(Renal Fluid Electrolyte Physiol. 11):F532-F543.

23. Schwartz, G. J., and Q. Al-Awqati. 1985. Carbon dioxide causes exocytosis of vesicles containing $\mathrm{H}^{+}$pumps in isolated perfused proximal and collecting tubules. J. Clin. Invest. 75:1638-1644.

24. Harris, R. C., J. L. Seifter, and B. M. Brenner. 1984. Adaptation of $\mathrm{Na}^{+}-\mathrm{H}^{+}$exchangers in renal microvillus membrane vesicles. J. Clin. Invest. 74:1979-1987. 